\title{
The Values of Incentive Regulations and Comprehensive Framework for Electrical Asset Management: An Iranian/Tehran Province Perspective
}

\author{
Reza Dashti ${ }^{1}$ \\ ${ }^{1}$ School of Electrical Engineering, Iran University of Science and Technology, Tehran, Iran \\ Correspondence: Reza Dashti, School of Electrical Engineering, Iran University of Science and Technology, \\ Tehran, Iran. E-mail: rezadashti83@yahoo.com
}

Received: February 23, 2014 Accepted: April 15, 2014 Online Published: October 26, 2014

doi:10.5539/emr.v3n2p74

URL: http://dx.doi.org/10.5539/emr.v3n2p74

\begin{abstract}
Asset management framework and its incentive economic equations are represented in this paper. To this end, asset management process conducted to realize distribution targets, are considered and a comprehensive framework of these activities is represented. This framework can be utilized in planning and evaluation of distribution system. On the basis of asset management comprehensive framework, economic equations are formulated and regulation indices are determined. Afterwards, method that regulates key indices is described. This method is conformed to distribution targets. At the final step, numerical studies on Tehran Province Regional Electrical Distribution Company (TPREDC) are presented. In TPREDC activities were done with few incentives, therefore productivity and benefit had reduced. After implementation of proposed internal regulation, it can be seen that key indices have been improved.
\end{abstract}

Keywords: asset management, regulations, comprehensive framework, economic equations

\section{Introduction}

\subsection{Research Necessity}

Electrical Distribution System Asset Management (EDSAM) is very important to achieve economic stability of this system. Having various activities, a wide network and numerous external factors with high impact, much number of assets, effect of human factors as motivation and education, asset management is very complicated (Reza, Saeed, \& Hassan, 2010; Reza, Saeed, \& Farid, 2010). Thus, in order to improve the performance of distribution system, it is of crucial importance to analyze activities, reconstruct distribution management structure and also index based regulation for each process.

Management Separation and decentralization can make EDSAM easy. For example, asset management and marketing activities have to be separated in power distribution companies. For each part, distinct rules and regulations have to be compiled so that private companies responsible for each class of activities and have enough motivation to improve indications and investments. This technique needs rules, regulation, planning and supervision.

\subsection{Litterateur Review and Comparison}

Ref (Tanure, Tahan, \& Lima, 2006) proposes a procedure and methodology for performance target setting related to continuity metrics in electricity distribution networks. Ref (Rudnick \& Donoso, 2000) assesses the Chilean "model company" regulation that aims at making the private distribution monopoly compete with a reference efficient model company, through a "yardstick competition" approach. Ref (Jamasb \& Pollitt, 2007) reviews the recent experience of the UK electricity distribution sector under incentive regulation. The aim of Ref (Kinnunen, 2006) is to study the ex post regulatory system in Finland in context of investment incentives. Ref (Jamasb \& Pollitt, 2008) examines the incentive properties and related aspects of the reference firm model-Network Performance Assessment Model - as used in Sweden and compares this with frontier-based benchmarking methods. Ref (Frías, Gómez, Cossent, \& Rivier, 2009) analyzes how traditional regulation of distribution system operators has to be improved to accommodate higher levels of distributed generation. In this paper, a new method for regulation of separated parts of Distribution Companies (DISCOs) has been presented. 
In many studies, incentive regulations for improving services and efficiency are provided for distribution asset managers. Ref (Carvalho \& Ferreira, 2005) uses a matured evolutionary-based application to search for the optimum tradeoff between individual quality of service and system reliability. It is becoming very important to be able to demonstrate and quantify the necessity and benefit of particular investment and operational decisions in electricity distribution systems, particularly in the context of service quality (Strbac \& Allan, 2001). Ref (Giannakis, Jamasb, \& Pollitt, 2005) presents a quality-incorporated benchmarking study of the electricity distribution utilities in the UK between 1991/92 and 1998/99. The objective of (Ajodhia, Schiavo, \& Malaman, 2006) is to evaluate the effectiveness of this system by studying the effects of regulation on the electricity distribution industry and to identify scope for improvement of the regulation in subsequent regulatory periods. The statistical two-sample t significance test presented in ( $\mathrm{Li}, \mathrm{Su}, \&$ Shen, 2009) can be used to determine the cause-and-effect relationships that exist between the covered rates and the reliability indices including public safety. However, this paper represents a comprehensive framework for asset management, leaving power business apart. This framework can be used in planning, inspection and evaluation of asset managers.

Some studies investigate planning, supervision and assessment of asset managers. Ref (El-Fouly, Zeineldin, El-Saadany, \& Salama, 2008) presents a new planning optimization model for distribution substation sizing, and timing. Ref (Das, 2008) presents a genetic algorithm based fuzzy multi-objective approach for determining the optimum values of fixed and switched shunt capacitors to improve the voltage profile and maximize the net savings in a radial distribution system. In Ref (Kaur \& Sharma, 2008), a generalized model for optimal multi conductor size selection in planning of radial distribution system planning is presented. Ref (Singh \& Goswami, 2009) presents new methodology based on nodal pricing for optimally allocating distributed generation for profit, loss reduction, and voltage improvement including voltage rise phenomenon. The dispatch of capacitors in distribution systems for daily operation is investigated in Ref (Wu, Zhang, \& Lo, 2009). This paper propose target base framework to plan, supervise and assess distribution system comprehensively and can be criteria in distribution system studies.

Some papers study economic relations of distribution studies. Ref (Lima, Noronha, Arango, \& dos Santos, 2002) focuses on the distribution pricing methods and suggests one that is currently under development in Brazil. Ref (Arocena, Contín, \& Huerta, 2002) analyses the distribution of benefits between firms and consumers due to the price regulation of the Spanish energy sectors (electricity, oil fuels and gas) during the decade 1987-1997. Ref (Lowry \& Getachew, 2009) presents the index logic that underpins this rationale in North American plans and offers two statistical approaches - indexing and benchmarking - that play a role in determining industry and/or national productivity trends and economy and/or industry input price trends that are used to track the unit cost of the industry. The main methodologies used in electricity price forecasting have been reviewed in Ref (Aggarwal, Saini, \& Kumar, 2009). Ref (Chandramohan, Atturulu, Kumudini, \& Venkatesh, 2010) uses a non-dominated sorting genetic algorithm (NSGA) for reconfiguring a radial Disco to minimize its operating costs considering real and reactive power costs while maximizing its operating reliability and satisfying the regular operating constraints. In Ref (Ketabi, Alibabaee, \& Feuillet, 2009), the production cost of reactive power and investment cost of capacitor banks were included into the objective function of the optimal power flow problem.

\subsection{Research Questions}

An important application of having a comprehensive framework for asset management in power distribution is using it in balanced economic equations to regulate separated parts of DISCOs. The criterion used to determine the relationships based on the expected distribution indices is quite flexible so that it can provide the asset manager with enough motivations to realize power distribution targets. Therefore, compared with other studies in this area, the proposed method has the following preferences:

- Comprehensive compilation of regulations and activities

- Balanced compilation of regulations and activities

- Compilation of regulations and activities in accordance with the targets of power distribution company

This paper contains the following sections: in the section 2, the targets of power DISCOs are represented. The framework of asset management is covered in the section 3. Section 4 includes comprehensive economic equations and motivations to regulate asset manager. Numerical studies in TPREDC conducted with proposed model in the section 5. Finally, section 6 covers the conclusions.

\section{Distribution Targets}

According to ref (Reza \& Saeed, 2010), DISCOs are expected to operate as economic enterprises. Therefore, their targets are specified respecting the profits of their stakeholders. Major stakeholders of distribution 
companies are customers, shareholders and the society, each of which has a different set of targets. Using the common language of asset, frameworks for power distribution tariffs, power market regulations and controlling tools are provided so that they can be easily utilized by distribution economic institutions in order to execute activities defined by the distribution asset management framework and also can guarantee the profits of the shareholders.

Distribution Company as an economic institution has to undertake the obligations defined by the government respecting the price determined in tariff strategy. This requires asset management planning in distribution system. Such planning suggests either developing the distribution network or keeping up with the current assets. In result, electricity targets, which can also be considered as power distribution targets, are expressed as follows:

- $\quad$ Best service or service improvement

- Min money or efficiency improvement

- Customer asserts and environment

Asset management targets have to comply with distribution targets. Thus, it requires various infrastructures to realize the mentioned targets. These infrastructures are divided into three major categories including engineering, information and management.

Distribution targets can be demonstrated as Figure 1, in which the targets restricting DISCO are removed and replaced by operational targets aimed at asset improvement.

In this section, structure of process implementation to realize distribution targets are investigated.

\section{Asset Management Framework}

Asset management mainly includes development and operation activities. Both of them have to be planned in a way that distribution targets are achieved in the most economic way. The diagram of asset management activities aimed to realize its targets are as represented in Figure 2.

As one can see, Figure 2 shows the general scheme of asset management. The corresponding Master Plan is provided in Figure 4.

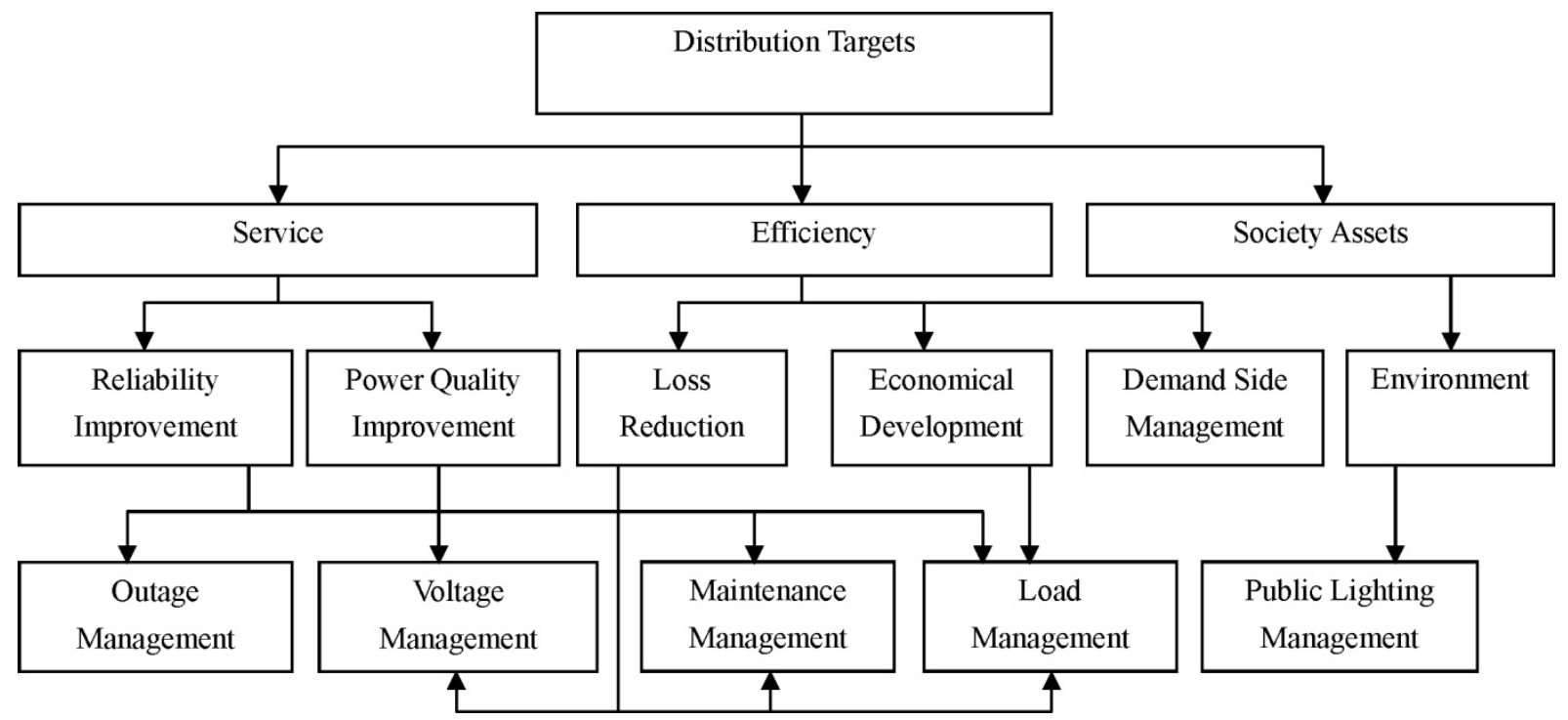

Figure 1. Distribution targets implementation 


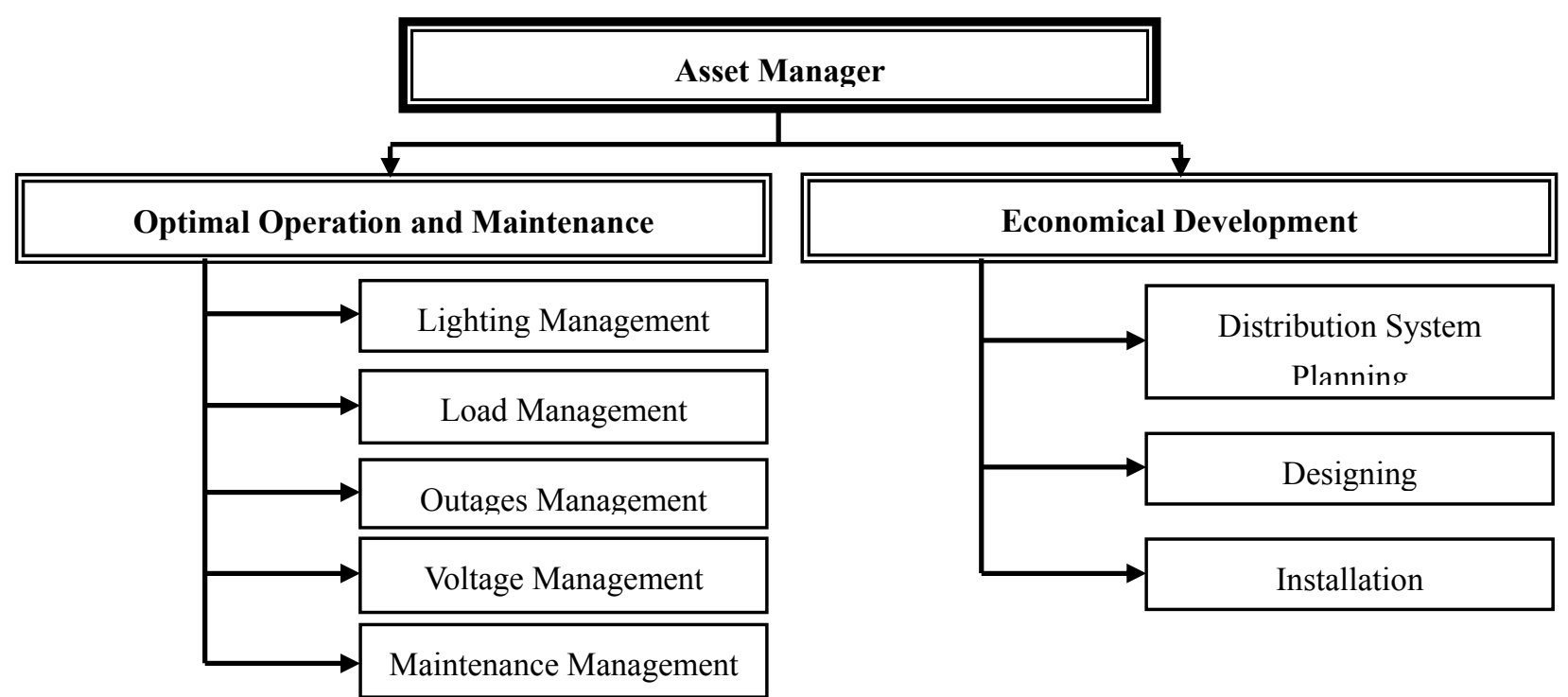

Figure 2. Asset manager structure aimed to realize asset management targets

\section{Asset Management Economic Equations}

There are different scenarios regarding asset management:

Scenario1: In this scenario, planning is conducted by another company and the asset manager is only responsible for network operation. In this case, studies and plans are done based on three lines of time, human resources and financial resources. Moreover, financial and penalty records are defined according to the framework aimed to realize scheduled targets. This scenario is project-oriented and is applicable in outsourcing while the incumbency stays in distribution company.

Scenario2: This scenario tries to approximate asset manager equation to the power marketing equation. To this end, indices of increasing energy efficiency in power distribution are defined as the basic indices of the outcome of asset manager. Afterwards, the cost of increasing each unit of efficiency is determined by efficiency promoting activities. In this case, planning is undertaken by the asset manager. This scenario is result-oriented and the incumbency is granted to the asset manager.

The second scenario has the following benefits:

- In medium- and long-term transfer of asset management to private sector, this sector conducts studies on investment and its rate of return and long-term planning. Consequently, huge investments are provided for asset management and thereby, indices are improved.

- Regarding their nature, power distribution networks have to be constantly monitored and decisions have to be made locally. Thus, scenario 2 plays an important role in increasing the efficiency.

- Outages and wastages of the power distribution network affect every aspect of distribution plans. Proposed method improves reliability indices and other distribution indices simultaneously. Therefore, outages and wastages are reduced with proposed method.

In this section, economic indices required to implement scenario 2 are designed. To this end, the indices related to distribution targets are defined based on the Table 1 . 
Table 1. Distribution targets and indices

\begin{tabular}{|c|c|c|c|c|c|c|}
\hline & Service & & & Efficiency & Environment & restrictions \\
\hline $\begin{array}{l}\text { Distribution } \\
\text { Targets }\end{array}$ & $\begin{array}{l}\text { Voltage } \\
\text { improvement }\end{array}$ & Reliability & & $\begin{array}{l}\text { Reduction } \\
\text { of loss }\end{array}$ & $\begin{array}{l}\text { Improvement } \\
\text { of lighting }\end{array}$ & - \\
\hline $\begin{array}{l}\text { Corresponding } \\
\text { indices }\end{array}$ & $\begin{array}{l}\text { Complaints on } \\
\text { voltage quality }\end{array}$ & $\begin{array}{l}\text { Energy } \\
\text { not } \\
\text { supplied }\end{array}$ & $\begin{array}{l}\text { Coordination } \\
\text { with } \\
\text { dispatching }\end{array}$ & Loss factor & lighting factor & $\begin{array}{l}\text { Complaints } \\
\text { and wastages }\end{array}$ \\
\hline
\end{tabular}

Some of the above-mentioned indices require investment and regulation while some other are considered as operational restrictions, which are of crucial importance in all classes of activities and targets. Using following function, restriction indices are calculated as a number between zero and one:

$\alpha=$ Fconstraint (the absence of reports, complaints, safety, etc.)

However, investment compensation is calculated by function $F$ using the following relation:

$F=$ Reliability improvement $\left(F_{1}\right)+$ Loss reduction $\left(F_{2}\right)+$ Lighting operation $\left(F_{3}\right)$

$I C_{1}=F_{1}$ (Reliability improvement $)=(E T+P M \beta+L M \gamma) \times \theta \times E \times T O \times 10^{-4}(\$)$

TO $=\left(1+\frac{\text { scheduled energy not supplied }}{E}\right)$

$I C_{2}=F_{2}($ Loss reduction $)=3.5 \times L S \times E \times 10^{-4}(\$)$

$I C_{3}=F_{3}$ (Lighting operation $)=P U B \times($ Lighting factor $)$

$L S:$ loss factor

$E T$ : Cost of outage management per $\mathrm{kWh}$

$P M$ : Cost of maintenance management per $\mathrm{kWh}$

$L M$ : Cost of load management per $\mathrm{kWh}$

$\beta, \gamma$ : Supervision factor

$\mathrm{E}$ : Amount of energy delivery per $\mathrm{kWh}$

TO: Indictor of scheduled outages and generation shortage

$\theta$ : Indicator of the reliability regulation, which is obtained using the following curve and relation

PUB: Cost of lighting management in terms of $\$$

$L S$ and $\theta$ have to be defined in a way that in addition to considering investment costs and providing satisfactory investment rate of return encourage the distribution companies to invest with the aim of improving the indices. Therefore, these functions are formed as described below.
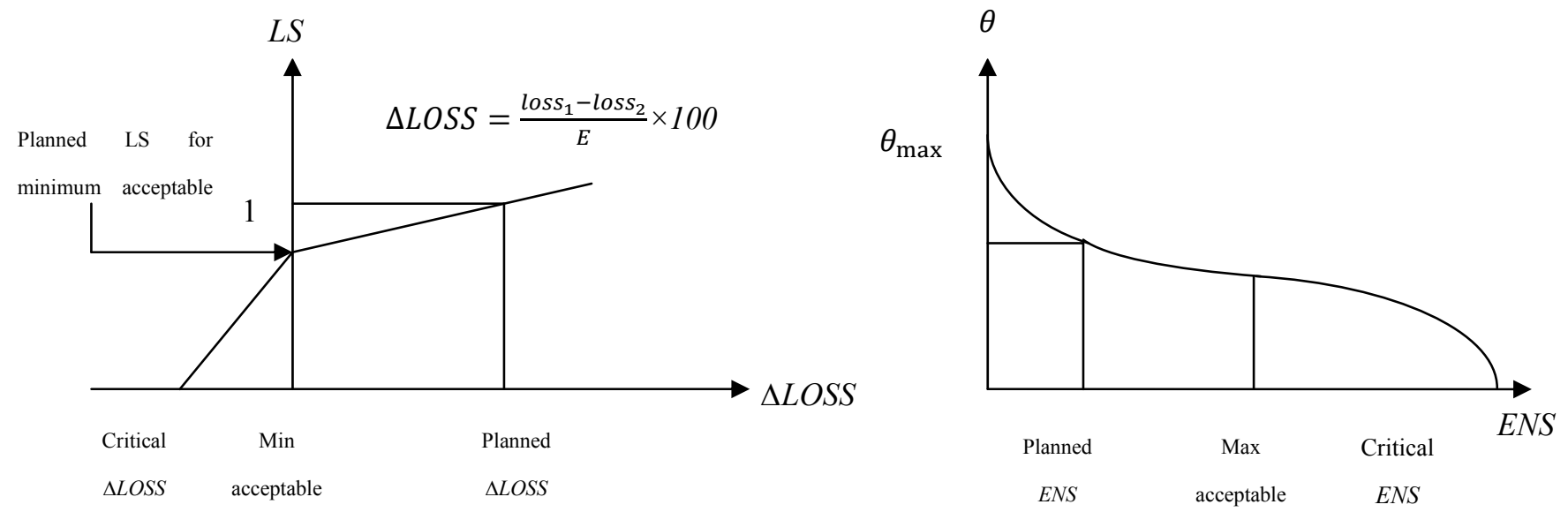

Figure 3. $L S$ and $\theta$ function 
As one can see, functions $L S$ and $\theta$ play a key role in regulation the activities and encouraging the asset manager that manage with private sector to accurately plan the investments and optimal conduction of the processes. Thus, the following method is used to define $L S$ and $\theta$.

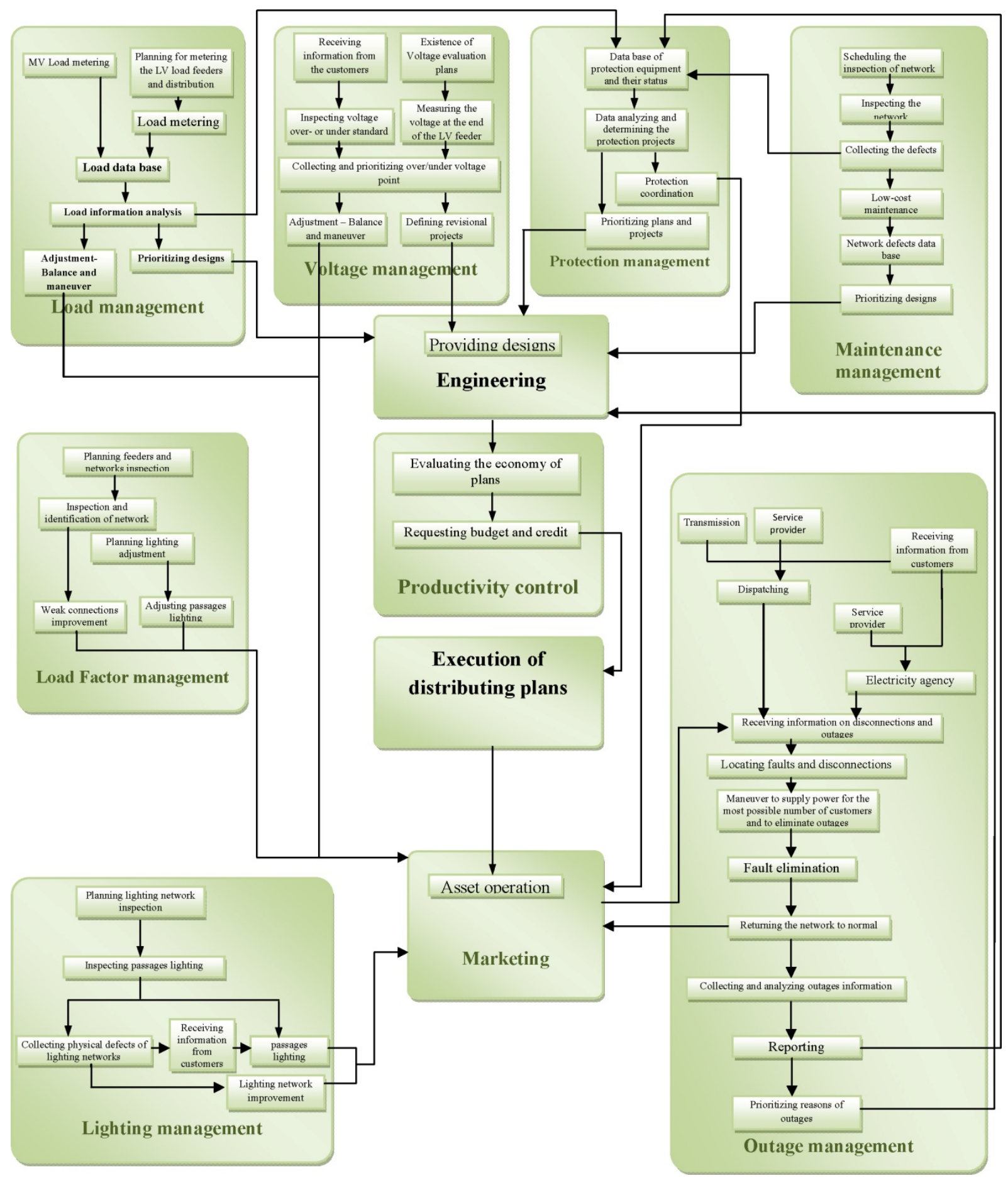

Figure 4. Asset management process

1- Determining the mount Loss and ENS in the last year.

2. Determining the target amount of Loss and ENS for the next year.

3. Determining the acceptable increment of Loss and ENS in the absence of investment 
4. Determining critical amounts of ENS and Loss

\section{Formulation}

$\theta$ formula can be defined in three periods as follows that shown in Figure 3.

$\theta=\left\{\begin{array}{lr}\theta_{\text {max }} e^{a_{1} \times E N S} & 0 \leq E N S \leq \text { Previous ENS } \\ a_{2} \times E N S+a_{3} & \text { Previous ENS } \leq \text { ENS } \leq \text { Maximum acceptable ENS } \\ a_{4} e^{a_{5} E N S-a_{6}}+a_{7} & \text { Maximum acceptable ENS } \leq \text { ENS } \leq \text { critical ENS }\end{array}\right\}$

$L S$ formula can be defined in three periods as follows and shown in Figure 3.

$L S=\left\{\begin{array}{lc}b_{1} \Delta \text { LOSS }+b_{2} & \text { Maximum acceptable } \triangle \text { LOSS } \leq \Delta L O S S \leq \text { critical } \Delta L O S S \\ b_{3} \Delta \text { LOSS }+b_{4} & \text { Critical } \triangle L O S S \leq \Delta L O S S \leq \text { Maximum acceptable } \triangle L O S S\end{array}\right.$

Indices $a_{i}$ in $\theta$ and $b_{i}$ in $L S$ regulate the investments aimed to execute the processes and grow with inflation rate. They reduce the costs that required improving distribution indices and depending on the acceptable, critical and last year amounts of ENS and Loss.

The three parts considered in functions $L S$ and $\theta$ work in a way that threat the investor to stop investing and encourage him to invest.

In result, the method of regulation economic function works as follows:

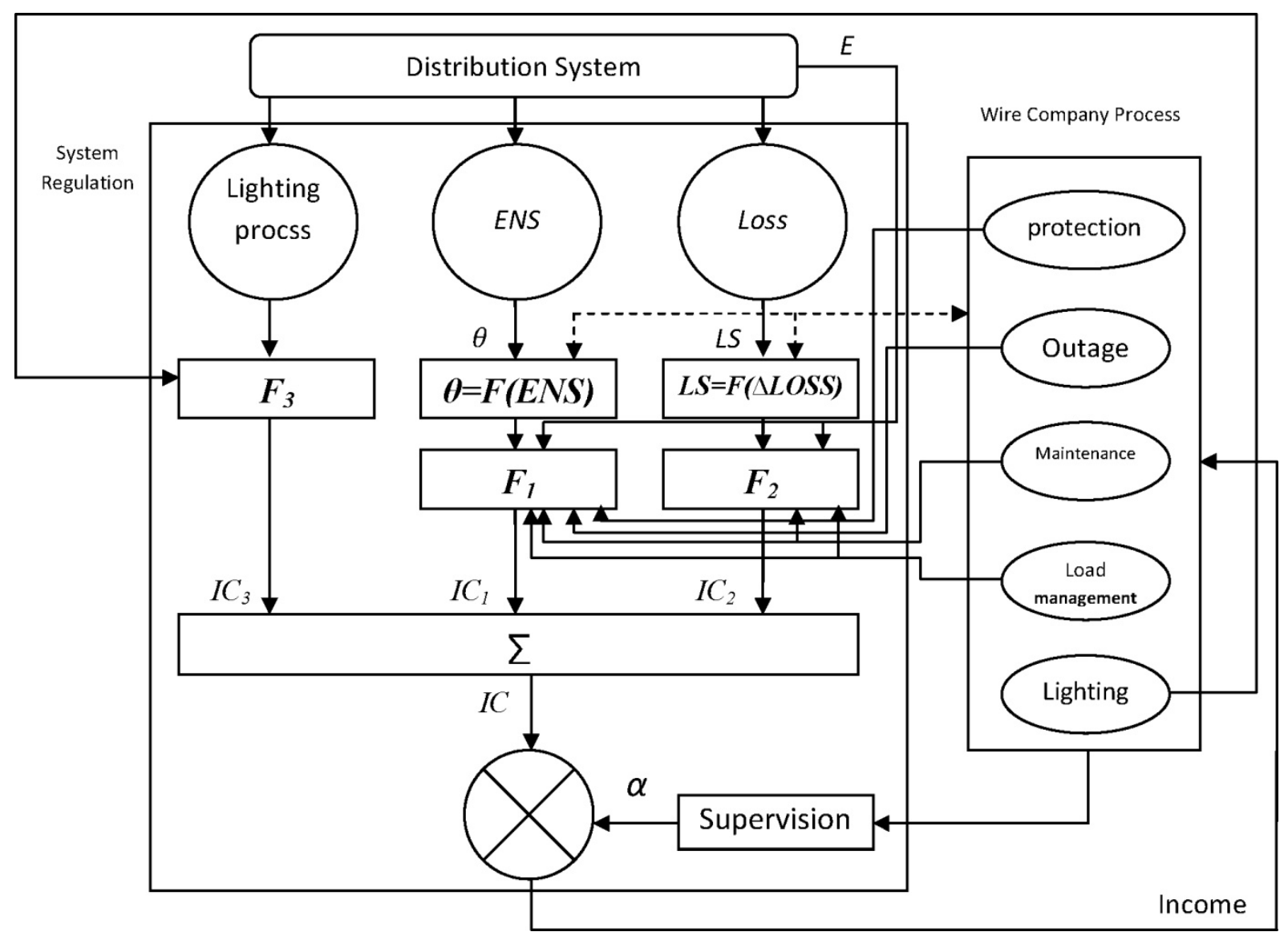

Figure 5. Regulation economic function

\section{Numerical Studies}

Numerical studies were conducted in TPREDC and in Chahar-Dangeh region, the information of which is represented as follows. The current state of indices and next year targets for Chahar-Dangeh region is as follows. Thus, parameters of functions LS and $\theta$ are determined using following equation: 
Table 2. Equipment used in Chahar-Dangeh region at the end of 2008

\begin{tabular}{llll}
\hline No. & Equipment & Unit & Quantity \\
\hline 1 & Area of Chahar-Dangeh & Square Kilometers & 134 \\
2 & Number of customers & Customer & 33354 \\
3 & Number of personnel & Person & 19 \\
4 & Number of air substations & Substation & 1350 \\
5 & Number of ground substations & Substation & 95 \\
6 & Length of air medium-voltage line & Kilometer & 390 \\
7 & Length of ground medium- voltage line & Kilometer & 36 \\
8 & Length of air low- voltage line & Kilometer & 630 \\
9 & Length of ground low- voltage line & Kilometer & 240 \\
10 & Number of public medium-voltage feeders & Feeder & 36 \\
11 & Number of low- voltage feeders & Feeder & 3080 \\
\hline
\end{tabular}

Table 3. Result of asset management regulation

\begin{tabular}{lcc}
\hline & Real data in 2009 & Planned data for 2010 \\
\hline LOSS & 26.7 & 24 \\
ENS & 1.99 & 0.9 \\
Lighting factor & 0.92 & 0.93 \\
Safety & 1 & - \\
compliant & 27 & 10 \\
\hline
\end{tabular}

$\theta_{\text {max }}=1.35$

Planned $E N S=1$

Maximum Acceptable $E N S=2$

Critical $E N S=8$

$a_{1}=-0.3, a_{2}=-0.1, a_{3}=1.1, a_{4}=-1.1, a_{5}=0.0625, a_{6}=-0.125, a_{7}=2$

Planned $\triangle L O S S=2$

Minimum Acceptable $\triangle L O S S=0$

Critical $\triangle L O S S=-2$

$b_{1}=0.95, b_{2}=1.9, b_{3}=0.0125, b_{4}=0.95$

After implemented in Chahar-Dangeh, indices changes as Figure 6. As one can see, the above-mentioned relations provide the asset manager with sufficient motivation to improve indices and thereby, distribution targets have been improved. 


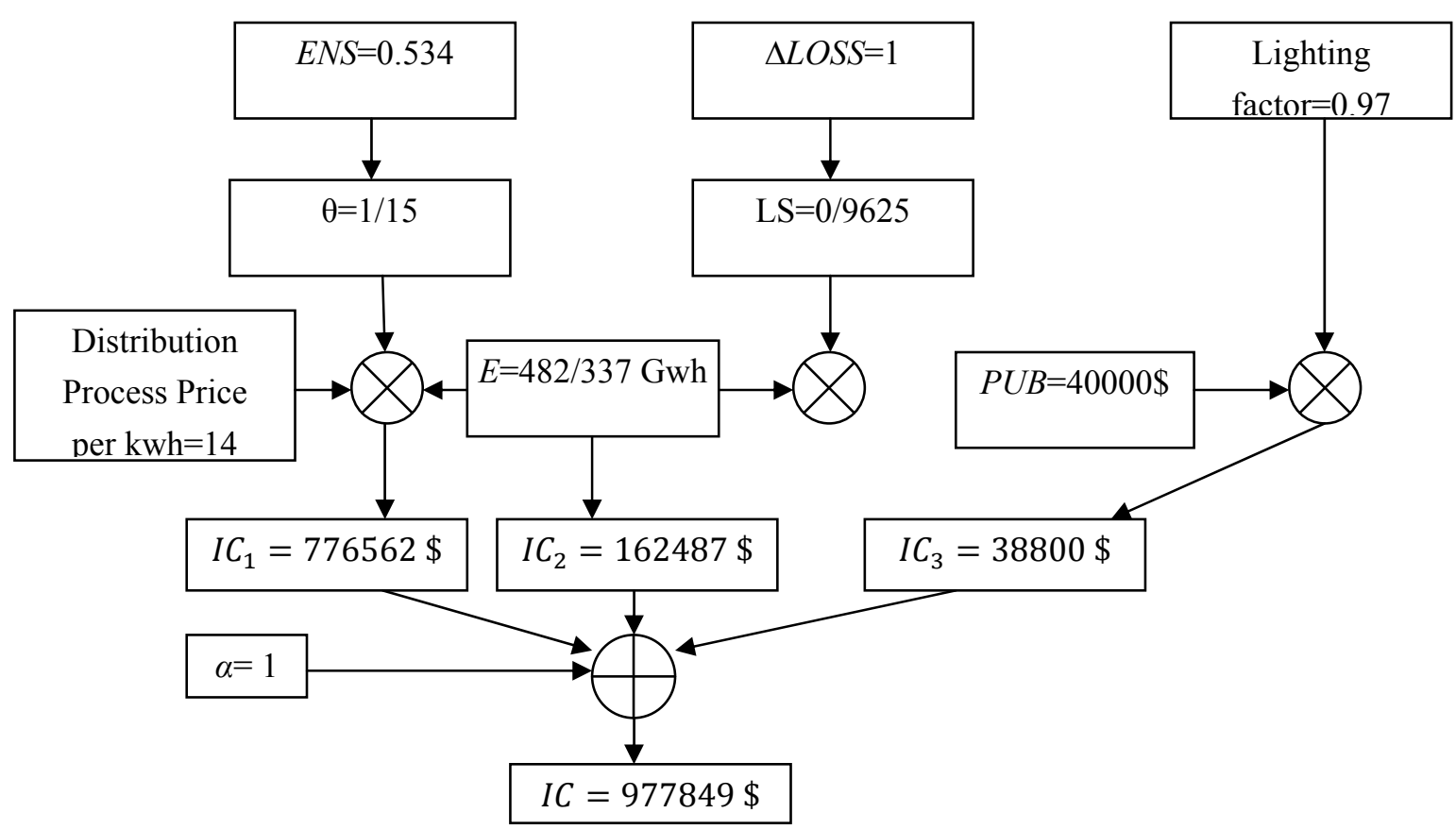

\section{Discussion}

Figure 6. Numerical results diagram

Results Shows that we must separate the parts of Distribution activities and regulate them with economic equations. This task can motivate system's player to improve their process. Also faults, system's defects and improvable points can be found easily. Proposed model can be used to price cap regulation and marginal cost reduction through indices planning. Also proposed model can be applied to meter external factors' effects and therefore manage them.

\section{Conclusion}

This paper represented a comprehensive framework for asset management activities. This framework provides the means to plan and evaluate the promotion of distribution targets. Using the represented framework, asset management economic equations were clarified and important indices of increasing the incentives of the asset manager company were determined. In the proposed method, distribution targets and the corresponding indices were used as the criterion of tuning the indices so that the distribution targets can be tuned by specifying the required regulations. Thus, distribution targets, activities and indices can be promoted and controlled using this method. At the final step, the method was implemented in a sample region and the results indicated the sensible improve of indices.

Comprehensive, balanced and target-compatible tuning is of the benefits of the proposed method over other methods. This method improves customer services, increases efficiency and leads to energy distribution in the most economic possible way.

\section{References}

Aggarwal, S. K., Saini, L. M., \& Kumar, A. (2009). Electricity price forecasting in deregulated markets: A review and evaluation. International Journal of Electrical Power \& Energy Systems, 31, 13-22. http://dx.doi.org/10.1016/j.ijepes.2008.09.003

Ajodhia, V., Schiavo, L. L., \& Malaman, R. (2006). Quality regulation of electricity distribution in Italy: An evaluation study. Energy Policy, 34, 1478-1486. http://dx.doi.org/10.1016/j.enpol.2004.11.016

Arocena, P., Contín, I., \& Huerta, E. (2002). Price regulation in the Spanish energy sectors: Who benefits? Energy Policy, 30, 885-895. http://dx.doi.org/10.1016/S0301-4215(01)00148-3

Carvalho, P. M. S., \& Ferreira, L. A. F. M. (2005). Distribution quality of service and reliability optimal design: Individual standards and regulation effectiveness. IEEE Transactions on Power Systems, 20, 2086-2092. http://dx.doi.org/10.1109/TPWRS.2005.857384

Chandramohan, S., Atturulu, N., Kumudini, D. R. P., \& Venkatesh, B. (2010). Operating cost minimization of a radial distribution system in a deregulated electricity market through reconfiguration using NSGA method. 
International Journal of Electrical Power \& Energy Systems, 32, $126-132$. http://dx.doi.org/10.1016/j.ijepes.2009.06.023

Das, D. (2008). Optimal placement of capacitors in radial distribution system using a Fuzzy-GA method. International Journal of Electrical Power \& Energy Systems, 30, 361-367. http://dx.doi.org/10.1016/j.ijepes.2007.08.004

El-Fouly, T. H. M., Zeineldin, H. H., El-Saadany, E. F., \& Salama, M. M. A. (2008). A new optimization model for distribution substation siting, sizing, and timing. International Journal of Electrical Power \& Energy Systems, 30, 308-315. http://dx.doi.org/10.1016/j.ijepes.2007.10.002

Frías, P., Gómez, T., Cossent, R., \& Rivier, J. (2009). Improvements in current European network regulation to facilitate the integration of distributed generation. International Journal of Electrical Power \& Energy Systems, 31, 445-451. http://dx.doi.org/10.1016/j.ijepes.2009.03.001

Giannakis, D., Jamasb, T., \& Pollitt, M. (2005). Benchmarking and incentive regulation of quality of service: An application to the UK electricity distribution networks. Energy Policy, 33, $2256-2271$. http://dx.doi.org/10.1016/j.enpol.2004.04.021

Jamasb, T., \& Pollitt, M. (2007). Incentive regulation of electricity distribution networks: Lessons of experience from Britain. Energy Policy, 35, 6163-6187. http://dx.doi.org/10.1016/j.enpol.2007.06.022

Jamasb, T., \& Pollitt, M. (2008). Reference models and incentive regulation of electricity distribution networks: An evaluation of Sweden's Network Performance Assessment Model. Energy Policy, 36, 1788-1801. http://dx.doi.org/10.1016/j.enpol.2008.01.034

Kaur, D., \& Sharma, J. (2008). Optimal conductor sizing in radial distribution systems planning. International Journal of Electrical Power \& Energy Systems, 30, 261-271. http://dx.doi.org/10.1016/j.ijepes.2007.07.005

Ketabi, A., Alibabaee, A., \& Feuillet, R. (2009). Application of the ant colony search algorithm to reactive power pricing in an open electricity market. International Journal of Electrical Power \& Energy Systems, 16.

Kinnunen, K. (2006). Investment incentives: Regulation of the Finnish electricity distribution. Energy Policy, 34, 853-862. http://dx.doi.org/10.1016/j.enpol.2004.08.034

Li, M. B., Su, C. T., \& Shen, C. L. (2009). The impact of covered overhead conductors on distribution reliability and safety. International Journal of Electrical Power \& Energy Systems, 25.

Lima, J. W. M., Noronha, J. C. C., Arango, H., \& dos Santos, P. E. S. (2002). Distribution pricing based on yardstick regulation. IEEE Transactions on Power Systems, 17, 198-204. http://dx.doi.org/10.1109/59.982214

Lowry, M. N., \& Getachew, L. (2009). Price Control Regulation in North America: Role of Indexing and Benchmarking. The Electricity Journal, 22, 63-76. http://dx.doi.org/10.1016/j.tej.2008.12.004

Reza, D., \& Saeed, A. (2010). Demand Response Regulation Modeling Based on Distribution System Asset Efficiency. Electric Power Systems Research.

Reza, D., Saeed, A., \& Farid, G. (2010). Asset Governance Assessment for Analyzing Affect of Subsidy on Marginal Cost In Electricity Distribution Sector. Energy.

Reza, D., Saeed, A., \& Hassan, G. (2010). A new long term load management model for asset governance of electrical distribution systems. Applied Energy, 87(12), 3661-3667. http://dx.doi.org/10.1016/j.apenergy.2010.04.003

Rudnick, H., \& Donoso, J. A. (2000). Integration of price cap and yardstick competition schemes in electrical distribution regulation. IEEE Transactions on Power Systems, 15, 1428-1433. http://dx.doi.org/10.1109/59.898123

Singh, R. K., \& Goswami, S. K. (2009). Optimum allocation of distributed generations based on nodal pricing for profit, loss reduction, and voltage improvement including voltage rise issue. International Journal of Electrical Power \& Energy Systems, 16.

Strbac, G, \& Allan, R. N. (2001). Performance regulation of distribution systems using reference networks. Power Engineering Journal, 15, 295-303. http://dx.doi.org/10.1049/pe:20010604 
Tanure, J. E. P. S., Tahan, C. M. V., \& Lima, J. W. M. (2006). Establishing quality performance of distribution companies based on yardstick regulation. IEEE Transactions on Power Systems, 21, 1148-1153. http://dx.doi.org/10.1109/TPWRS.2006.879283

Wu, W. C., Zhang, B. M., \& Lo, K. L. (2009). Capacitors dispatch for quasi minimum energy loss in distribution systems using a loop-analysis based method. International Journal of Electrical Power \& Energy Systems, 11 .

\section{Copyrights}

Copyright for this article is retained by the author(s), with first publication rights granted to the journal.

This is an open-access article distributed under the terms and conditions of the Creative Commons Attribution license (http://creativecommons.org/licenses/by/3.0/). 